Catarina Carvalheiro, Ana Luísa Costa, Rita Marquilhas, Clara Pinto, Fernanda Pratas e Gael Vaamonde

\title{
A idade dos «desvios»: diacronia, variação social e linguística de corpus
}

\section{Introdução}

Entre os corpora diacrónicos de línguas ibero-românicas atualmente em construção, figura o caso do P.S., Post Scriptum ${ }^{1}$ doravante Post Scriptum, sediado no Centro de Linguística da Universidade de Lisboa e objeto deste trabalho. A sua cronologia é a da Idade Moderna -recolhem-se textos de um intervalo que se estende do século XVI ao início do século XIX- e as línguas em causa são o espanhol e o português. Com este corpus pretende-se constituir uma amostragem do uso das duas línguas nos seus espaços europeu e extraeuropeu ao longo daqueles séculos.

Com efeito, verifica-se ao nível das fontes históricas portuguesas e espanholas que a documentação oficial dos tribunais dos dois reinos conservou peças de especial relevância histórico-linguística: cartas particulares de gente diversa, muita dela gente vulgar. Ficaram arquivadas dentro de processos civis e, sobretudo, de processos criminais, e foram contextualizadas pelos próprios tribunais que as usaram como instrumento de prova para perseguir os respetivos autores, destinatários, ou indivíduos com eles relacionados.

Apesar de ser evidentemente variado o tipo de utilização a que se presta um recurso baseado em documentação que espelhe usos quotidianos da língua, ele é sobretudo um recurso novo para a perspetiva da Sociolinguística Histórica. Permite recolher dados abundantes e fidedignos no estudo da mudança linguística, abrindo a hipótese de uma fina reconstituição diacrónica da sua variação geográfica e social. Com fontes de tal natureza, e com esta facilidade de pesquisa, minimiza-se consideravelmente um risco conhecido em Linguística Histórica: o de se construir conhecimento pouco verificável do ponto de vista empírico. Terttu Nevalainen descreveu assim esse risco:

10 projeto P.S., Post Scriptum: Arquivo digital da escrita quotidiana em Portugal e Espanha na época moderna é financiado pelo Conselho Europeu de Investigação (7FP/ERC Advanced Grant 2011, Grant Agreement 295562).

Catarina Carvalheiro, Ana Luísa Costa, Rita Marquilhas, Clara Pinto, Fernanda Pratas e Gael Vaamonde: CLUL - Universidade de Lisboa 
[L]ooking for authentic material produced by individuals, the historical sociolinguist is faced with the fact that it is only available from the literate section of the population. This represents the tip of the iceberg at a time when the vast majority of the population was illiterate. As the social structures of an earlier era are not familiar to the researcher, they have to be reconstructed on the basis of social, demographic and economic history. Placing historical linguistic findings in their social contexts thus requires more back-ground information than those present-day studies in which the researchers are familiar with the communities they [study] (Nevalainen 2011, 281).

Pretende-se que os materiais do Post Scriptum contornem os problemas apontados na citação acima em função dos seguintes factos:

- incluem muitas cartas originais de natureza privada escritas por falantes semi-alfabetizados, não só por falantes letrados;

- incluem amostras de uso da língua por parte de atores sociais de estratos muito diversos;

- muitas das histórias de vida dos agentes em causa, tanto na sua faceta de falantes, como na de atores sociais, são do nosso conhecimento porque o próprio tribunal as investigou e reconstituiu;

- muitas situações de comunicação relacionadas com os documentos são também conhecidas, fruto da mesma investigação judicial.

O Post Scriptum estará finalizado em 2017, com uma envergadura de dois milhões de palavras - um milhão para cada língua-, mas a partir dos materiais já disponíveis, que ultrapassam meio milhão de palavras, é possível extrair amostras para fundamentação dos dois argumentos que queremos defender concretamente: i) o de que o conceito de desvio linguístico é facilmente desmontável com a demonstração da antiguidade de processos que, enquanto «desvios», costumam ser estigmatizados pelo público leigo; ii) o de que os atlas histórico-dialetais são um recurso linguístico que se pode realizar, hoje em dia, com um grau de incerteza cada vez mais insignificante. No presente artigo, após uma descrição sumária do Post Scriptum (secção 2), apresentaremos exemplos ilustrativos dos dois argumentos. Na secção 3, ocupamo-nos da existência de pois como marcador discursivo em usos não descritos nas gramáticas tradicionais. Na secção 4, do uso de cujo sem valor possessivo. Na secção 5, descrevemos o grau de difusão e a distribuição geográfica dos usos inovadores dos pronomes átonos da terceira pessoa em espanhol; estes usos não respeitam a função sintática do referente, traduzindo-se em fenómenos conhecidos como leísmo, laísmo e loísmo. Finalmente, na secção 6, apresentamos uma breve conclusão e perspetivas para trabalhos futuros. 


\section{Corpus Post Scriptum}

A equipa do Post Scriptum, formada por historiadores e linguistas portugueses e espanhóis, desempenha a tarefa de verificar milhares de processos, desde os mais importantes, que são os da Inquisição, aos da justiça episcopal, da Coroa, periférica da Coroa, da Intendência da polícia e das ordens militares. O ordenamento jurídico do Antigo Regime oferece, com efeito, o panorama de um sistema plural, panorama esse que tinha raízes medievais e só desapareceu com a racionalização iluminista que acompanhou a instituição dos estados liberais no século XIX. Significa isto que havia muitas justiças paralelas na Idade Moderna. A Igreja tinha duas, a da Inquisição, que perseguia os crimes contra o $1 .^{\circ}$ mandamento, e a episcopal, que perseguia os outros «pecados», sendo que pecado e crime podiam ser conceitos sinónimos (Carvalho 1988). A justiça da Coroa, por seu lado, perseguia crimes contra a estabilidade do Estado e podia ser ministrada no centro dos reinos ou na periferia (caso da justiça periférica da Coroa, a cargo dos juízes de fora); a Intendência da Polícia velava pela segurança nas cidades; a das ordens militares era aquela onde tinham direito a ser julgados, como privilégio, os indivíduos com a distinção de cavaleiros. Havia, finalmente, mas também com grande protagonismo, a justiça local (Hespanha 2003).

O paralelismo entre estas justiças traduzia-se num considerável equilíbrio de poderes: «Cada corpo [era] provido de uma jurisdição que permit[ia] uma espécie de autogoverno: a possibilidade de ter magistrados próprios, a capacidade de julgar os seus próprios conflitos internos, o poder de fazer leis» (Camarinhas 2010, 19). Na Inquisição, por exemplo, apesar de a maioria dos processos ser de judaísmo, havia também processos movidos aos familiares do Santo Ofício que faltassem às suas obrigaçãos, ou a sujeitos externos que se fizessem passar por familiares do Santo Ofício. A variedade de documentação processual gerada por todo este sistema está, por conseguinte, bastante garantida, como garantido está um espelhamento verosímil do dinamismo da sociedade da época.

Em termos de faseamento e metodologia de trabalho, sempre que se depara nos arquivos com processos de qualquer daqueles tribunais que contenham cartas privadas enquanto prova instrumental, a equipa do Post Scriptum transcreve-as, digitaliza-as e edita-as em função dos mesmos cuidados que a crítica genética dedica ao manuscrito de autor literário (Grésillon 1994; Castro 2001). Trata-se, com efeito, de documentos originais que exibem vestígios materiais do processo da respetiva génese, ${ }^{2}$ sendo por isso mesmo extremamente ilustrativos

2 Algumas cópias são também transcritas, no caso de serem historicamente relevantes. Mas essas não integram o corpus linguístico anotado; só são utilizadas enquanto fontes históricas. 
dos juízos metalinguísticos dos falantes envolvidos. Reconstitui-se também a situação de comunicação e classificam-se sociologicamente, com o máximo possível de dados, os perfis de autores e destinatários, com base no que ficou indicado pelos tribunais que recolheram aqueles documentos.

A digitalização do facsímile da carta, a transcrição e a edição, bem como as bases de dados históricos e biográficos associados, são todos eles recursos tornados acessíveis num ambiente online que permite não só a edição interativa, como a anotação automática e uma potente busca cruzada na plataforma TEITOK (Janssen 2014), ${ }^{3}$ especialmente construída para processar documentos em formato XML-TEI, que é o formato adotado pelo Post Scriptum. ${ }^{4}$ O TEITOK tem incorporado um sistema, originário do CorpusWiki, ${ }^{5}$ que permite que as tarefas de modernização ortográfica, lematização, anotação morfossintática e alinhamento com a anotação sintática sejam automaticamente efetuadas, não dispensando, evidentemente, um refinamento manual.

Quanto à edição digital propriamente dita, ela cabe na categoria a que se vem chamando, em Humanidades Digitais, «edição digital documentária», composta pela fonte, pelos resultados do seu tratamento editorial e pelas ferramentas informáticas que permitiram que o mesmo tratamento se processasse (Pierazzo 2011). Assim, qualquer investigador pode replicar todas as experiências já feitas com os mesmos dados.

Na anotação morfossintática, adota-se o sistema de etiquetas Eagles, levemente modificado para garantir compatibilidade com recursos comparáveis, nomeadamente o corpus Tycho Brahe, ${ }^{6}$ CORDIAL-SIN ${ }^{7}$ e WOChWEL. ${ }^{8}$ Na anotação sintática, segue-se o sistema de anotação dos Penn Parsed Corpora of Historical English (Kroch/Santorini/Delfs 2004) mediante o recurso a um analisador sintático de base estatística (Collins 1999 e Bikel 2004) e a uma interface gráfica de edição da anotação, a ferramenta CorpusDraw, que integra o motor de busca CorpusSearch2, ${ }^{9}$ desenvolvido por Randall (2005-2007). Ambas as anotações, morfossintática e sintática, uma vez que estão alinhadas com a marcação do texto, são plenamente pesquisáveis em articulação com os dados extralinguísticos, sejam eles cronológicos, geográficos ou sociais.

3 Cf. http://alfclul.clul.ul.pt/teitok/site/index.php [última consulta: 06. 01. 2016].

4 Cf. http://ps.clul.ul.pt [última consulta: 06. 01. 2016].

5 Cf. http://www.corpuswiki.org/ [última consulta: 06. 01.2016].

6 Cf. http://www.tycho.iel.unicamp.br/corpus/ [última consulta: 06. 01. 2016].

7 Cf. http://www.clul.ul.pt/sectores/cordialsin/projecto_cordialsin.html [última consulta: 06. 01. 2016].

8 Cf. http://alfclul.clul.ul.pt/wochwel/index.html [última consulta: 06. 01. 2016].

9 Cf. http://corpussearch.sourceforge.net [última consulta: 06. 01. 2016]. 


\section{Pois como marcador discursivo}

O primeiro caso que apresentamos diz respeito a funções de pois ignoradas pelas gramáticas tradicionais e, consequentemente, excluídas da descrição gramatical consagrada a usos da variedade padrão.

\subsection{Pois na tradição gramatical}

Não é difícil encontrar, em gramáticas e dicionários, exemplos que permitem classificar pois como conjunção coordenativa explicativa ou análises que procuram explicar quer o seu estatuto ambíguo entre subordinador e coordenador, quer o seu valor causal ou explicativo (Brito 2003; Cunha/Cintra 1984; Lobo 2001 e 2013; Matos e Raposo 2013; Mendes 2013; Peres 1997; e.o.). Também se obtém com relativa facilidade, e nas mesmas obras de referência, informação sobre o valor conclusivo de pois, determinado pela sua ocorrência em posições intercaladas na frase. Além destas funções, associadas ao estabelecimento de conexões interfrásicas, pois é ainda reconhecido em instrumentos de normalização linguística como advérbio de afirmação, veiculando normalmente valor confirmativo.

O percurso histórico de pois, de advérbio a conjunção temporal, como no exemplo (1), a conjunção subordinativa causal, como no exemplo (2), a conjunção coordenativa causal/explicativa, como no exemplo (3), tem sido, igualmente, objeto de atenção de alguns estudos (Fiéis/Lobo 2009; Lima 2002, e.o.).

(1) Mando o meu salteyro grande a Jo(han) Ean(e)s, sucelareyro, q(ue) o aia elle en sua uida \& poys sua mort(e) que fique ao $\mathrm{m}(\mathrm{o}) \mathrm{est}(\mathrm{e}) \mathrm{i}(\mathrm{r}) \mathrm{o}$

(Doc. 55, Orense (1281); Maia 1986, 133)

(2) Outrossi pediu que pois o dito scudeiro nõ pagaua o dito trebuto ao dito Monsteiro que lhj abrisse mão das ssas herdades

(DN091 (1339); Martins 2001, 571)

(3) Andei mais devagar do que o normal, pois não havia razão para correr riscos.

(CRPC, O Jogo, apud Mendes 2013, 1732)

Contudo, o contacto com o nosso corpus de escrita do quotidiano, que preserva alguma proximidade com o género dialogal, torna evidente que o leque de funções enunciadas para pois é insuficiente para dar conta de todos os seus contextos de uso. Disso são exemplo as ocorrências de pois no excerto transcrito em (4).

(4) Pois vosa senhoria non fica Pobre / e non le sosedera mal Algum / Pois se nom me mandar le aguro pe/lo santisimo sacramento tamta / huma Parte como hotra P fica 
queima $^{\text {da }}$ / e para heste dinhiro som 20 e 4 [...] / omes e todos estam d espias e / e manda rar hotro emteregoro $\mathrm{m} / \mathrm{e}$ o portador esta Inosemte Pois / he mandado Pois os 20 e 4 estam / De Parte Pois se nom quer mam/dalas emPrestemas Pois obrigo ${ }^{\mathrm{me}}$ pe/la fe que Profeso demtero em ter / meses mandalas e sabera quem he / e me dara As Alvisas

(CARDS0004 (1825); CLUL 2014)

\subsection{Funções discursivas de pois}

Se pois tem, em alguns contextos, uma distribuição conjuncional e pode ser interpretado como tendo valor explicativo, como se pode verificar nas paráfrases em (5) e (6), nas quais se substituiu pois por porque, o mesmo não se aplica aos restantes contextos, como se atesta, por exemplo, na estranheza de (7).

(5) E o portador está inocente, porque é mandado.

(6) [...] se não quer mandá-las, empreste-mas, porque me obrigo, pela fé que professo, dentro em três meses mandá-las,

(7) \#Porque os 20 e 4 estão de parte. \#Porque, se não quer mandá-las, empreste-mas

A proposta de normalização (4') do excerto antes transcrito em (4) evidencia que alguns pois estão associados a fronteiras prosódicas com uma marcação diferente da de subordinadas explicativas. Em casos como os de (7), pois tem uma pausa ou quebra entoacional anterior mais acentuada, o que é comum entre marcadores discursivos (Fraser 1999; Martín Zorraquino/Portolés Lázaro 1999).

(4') Pois Vossa Senhoria não fica pobre e não lhe sucederá mal algum. Pois, se não me mandar, lhe juro, pelo Santíssimo Sacramento, tanta uma parte como outra fica queimada. E para este dinheiro são 20 e 4 [...] homes, e todos estão d'espias, e manda rar outro entregaram. E o portador está inocente, pois é mandado. Pois os 20 e 4 estão de parte. Pois, se não quer mandá-las, empreste-mas, pois obrigo-me, pela fé que professo, dentro em três meses mandá-las. E saberá quem é, e me dará as alvíssaras.

(Ed. modernizada, CARDS0004 (1825); CLUL 2014)

Crucialmente, estes pois estabelecem a ligação entre dois segmentos de discurso sem contribuir para a interpretação do conteúdo proposicional de nenhum dos segmentos, como acontece quando funciona como conjunção explicativa ou como advérbio conetivo conclusivo. A sua função parece antes ser a de orientar o ouvinte/leitor quanto à natureza da informação que introduz, tal como refere Fraser $(1999,946)$ relativamente a «marcadores discursivos que relacionam tópicos». Concretamente, pois parece desempenhar uma função de estruturação da 
informação, ao nível da tematização, assegurando a introdução de informação discursivamente nova e relevante para o mesmo tópico discursivo, que, em (4), é a entrega de dinheiro - tema dominante desta carta de extorsão.

Esta atuação de pois ao nível da estrutura temática e informacional não é a sua única função como marcador discursivo. Em Lopes (1991) apresenta-se uma identificação de funções a nível pragmático relativamente a contextos como (8), nos quais pois introduz, no português contemporâneo, um enunciado que consiste numa reação a um ato ilocutório anterior.

(8) - Estou com sono!

- Pois deita-te.

(Lopes 1991, 185)

Na análise do percurso diacrónico de pois, entre conjunção e marcador discursivo fático, Lima (2002) considera vários exemplos em que este marcador, à semelhança do que se observa em (8), introduz enunciados que instanciam reações a atos ilocutórios presentes no discurso precedente, como (9), um exemplo do século XVI.

(9) Ines Pereyra. Marido nam digo isso, Pe. Pois q(ue) dizeis vos molher Ines. Yr folgar onde eu quiser

(Gil Vicente, Inês Pereira, ed. C. A. Ribeiro, 1l. 1002-1004 apud Lima 2002)

\subsection{Um pois estruturador}

A análise dos pois existentes nas cartas portuguesas do Post Scriptum, além de atestar exemplos de usos conjuncionais e adverbais como os inicialmente descritos, e de registar um elevado recurso a pois como marcador discursivo, com diversas funções, permitiu identificar uma função de estruturador temático-informacional e perceber que esta especificação tem um uso crescente até ao século XX. Embora não haja eco da função de marcador discursivo estruturador nas gramáticas e estudos que se debrucem sobre os valores de pois, o seu uso parece ter sido produtivo no português da Idade Moderna e mantém-se ativo no português contemporâneo.

Os enunciados em (10), (11) e (12) incluem exemplos deste pois estruturador dos séculos XVIII, XIX e XX, respetivamente.

(10) eu pesote pelo amor deos q(ue) te Lenbres q(ue) eu sou teu marido pois torna a pedir a Senhora q(ue) pedia por mim que me valha

(CARDS0033 (1791), CLUL 2014) 
(11) [Munto estimarei que te tenhas tido felecidades Como eu p(ar)a mim dezejo i Juntamente em Comp(anhi)a da nosa Mai dos mais irmaus. $]_{\text {arenga }}$

Pois eu sahi da cidade do porto a dezoito de no(vem)bro de mil 818 i chiguei aqui a esta prisão de desta cida do Rio de jan(ei)ro Com trinta digo Com sesenta dias de viaige.

(CARDS7052 (1818), CLUL 2014)

(12) poues cá reçebim a aeçomenda que de lisboa poues esquzavas de andar a ecomodar esa xente poues a gente ca gozaramos pouco pela pascoa que a gente não tinha alegria para iço q estava pera açentar paraça o meu [N]

(FLY2153 (1917), Marquilhas 2010)

Destes exemplos, salienta-se que, em (11) e em (12), pois se encontra em início absoluto, anunciando um novo tópico discursivo; quando não se encontra em posição inicial absoluta, contribui para a progressão temática, introduzindo novas informações relativas ao tópico anterior.

Face à constatação da existência deste marcador discursivo, pelo menos desde o século XVIII, desenvolvemos uma análise exploratória da sua distribuição por século. Para isso, foi considerada uma amostra de cerca de 2095 cartas, das quais apenas 803 continham estruturas com pois, havendo 1912 ocorrências na totalidade. Devido à falta de equilíbrio da distribuição pelos diferentes séculos, classificaram-se cerca de cem estruturas por cada século. As cartas dos séculos XVII, XVIII e XIX pertencem ao Post Scriptum e as cartas do século XX estão disponíveis no corpus $F L Y .{ }^{10}$ Na tabela 1, sistematizam-se os resultados. ${ }^{11}$

Tabela 1: Ocorrências de pois estruturador por século

\begin{tabular}{l|r|r|r|r|r}
\hline Séculos & $\mathbf{X V I I}$ & $\mathbf{X V I I}$ & $\mathbf{X I X}$ & $\mathbf{X X}$ & Totais \\
\hline Estruturas analisadas & 105 & 101 & 101 & 112 & 419 \\
\hline Totais de pois estruturador & 0 & 10 & 18 & 33 & 61 \\
\hline$\%$ de pois estruturador & 0 & $9,9 \%$ & $17,8 \%$ & $29,5 \%$ & $14,5 \%$ \\
\hline
\end{tabular}

Os resultados apresentados confirmam a produtividade de pois como marcador discursivo estruturador nas interações discursivas do género epistolar, que podem ser entendidas como janelas temporais de registos menos formais do portu-

10 Cf. http://fly.clul.ul.pt/ [última consulta: 06. 01. 2016].

11 Uma análise mais detalhada dos dados do século XX, relativos ao corpus FLY, é apresentada em Costa (2014). 
guês da Idade Moderna. Esta análise contrapõe-se às descrições gramaticais tradicionais, que restringem as funções de pois, e ilustra a importância de se considerarem corpora linguísticos como o Post Scriptum para se evitarem marginalizações de alguns usos de língua.

\section{Cujo: ocorrências não canónicas em português a partir do século XVII}

O segundo exemplo que apresentamos é o da ocorrência do relativo cujo desprovido de valor possessivo, o que constitui um outro caso de estrutura linguística considerada marginal, embora consagrada pelo uso.

\subsection{Palavra relativa possessiva}

Em todas as fases da língua portuguesa, cujo está atestado como palavra relativa que exprime uma relação semântica de «posse material ou jurídica, mas também de parentesco ou relação entre a parte e o todo» (definição para o português contemporâneo em Raposo 2013, 906). Cumulativamente, cujo apresenta-se também, até ao séc. XVI, como uma variante de de quem, expressão relativa e interrogativa (cf. Martins 2003, 57).

(13) Emtam lhe pregumtou Lionel:

-Estes tindilhõões cujos sam?

(DSG172,1.18/ID)

Enquanto palavra relativa, cujo desempenha duas funções. Por um lado, retoma o antecedente nominal que corresponde ao possuidor, como ilustrado em (14):

(14) A Ana, cujo colar desapareceu, queixou-se à polícia.

(Veloso 2013, 2097)

Por outro lado, atribui uma interpretação definida ao «sintagma nominal que forma o constituinte relativo», sendo, assim, proibida a sua ocorrência com um determinante com valor (in)definido (15):

(15) *comprei um livro as cujas páginas vinham rasgadas.

(Veloso 2013, 2097) 


\subsection{Uso não possessivo}

Num registo muito específico do português europeu contemporâneo, encontramos, no entanto, um uso de cujo não possessivo, ilustrado em (16):

(16) [...] e foi a mulher quem salvou a situação oferecendo um copo de água à velhota e um anis ao senhor, cujo vestia um casaco de quarto agaloado, no fio, e calças creme compridas de mais [...]

(António Lobo Antunes, Fado Alexandrino, 1983)

Em Moreira (1907, 40), ficamos a saber a posição que este uso não possessivo de cujo suscita da parte das gramáticas normativas: «A fórma cujo apparece uma ou outra vez, todavia usada apenas por pessoas de limitada leitura e pretenciosas [e] por pessoas letradas, de certo por descuido» [...] «A sua construcção, porém, afasta-se da que é ensinada pelos grammaticos». Estas observações tomavam como exemplos frases como as que se seguem, de uma personagem criada por Camilo Castelo Branco, que é satirizada pelo autor:

(17) [...] tudo em nome do seu particular amigo José Bernardo e do mano conde, cujos, dizia, são meus íntimos [...]

(Camilo Castelo Branco, A Corja, 1880)

Curiosamente, no Post Scriptum, encontramos um cujo com uso semelhante ao que é condenado por Moreira (1907). Partindo de uma amostra de 800 cartas do Post Scriptum, verificamos que as atestações deste cujo não possessivo começam no século XVII.

(18) hum arratel de xá bom cujo he de preso 1600 [réis]

(CARDS2160 (177?), CLUL 2014)

O uso de cujo exemplificado em (18) parece equivaler ao uso de o qual, em (19), também ele expressão relativa não possessiva. Assumindo como hipótese de investigação uma possível alternância, na diacronia do português, entre as duas expressões pronominais, apresentamos o paralelismo entre cujo e o qual, partindo da descrição feita por Cardoso $(2008,2010,2011)$ sobre o uso de o qual, até ao século XVII, em contextos de coordenação especificante (de Vries 2002).

(19) entrego e outorgo. ao Mosteiro de san Saluador de Moreyra. Hũu casal que e en Rial de Pereyra. o qual casal a dita dona Mayor uëegas (... mandou ao dito Mosteiro.

(1282, Martins 2001)

De acordo com Cardoso, existem várias propriedades que permitem distinguir o uso de o qual em português europeu contemporâneo do seu uso enquanto coordenação especificante até ao século XVII. 
A primeira dessas propriedades diz respeito ao facto de o sintagma nominal em que estas expressões participam poder ou não ter um núcleo interno. Quando esse núcleo interno ocorre, pode ter uma forma diferente da do antecedente da expressão relativa. Verificamos que, tal como acontece com o qual, em (20), também o sintagma nominal encabeçado por cujo pode apresentar núcleo interno, lexicalmente diferente do seu antecedente. No exemplo (21), o antecedente «a quantia de Sem mil reis em moeda papel» é recuperado por «dinheiro».

(20) mostrarõ logo ẽ Jujzo húú testamẽto [...] na qual mãda fazía mẽçom Antre as outras coussas que A mãdara fazer Sancha gíl.

(1328, Martins 2001)
(21) intregara ao portador desta a quantia de Sem mil reis em moeda papel e fixadas dentro de huma carta pois he para livramento de hum nosso companheiro q(eu) se acha prezo nessa Cadeia e cujo

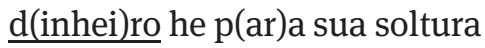

(CARDS0087 (1824), CLUL 2014)

Além disso, esse núcleo interno pode também ser modificado: em (22), o nome «casal», núcleo interno do sintagma nominal encabeçado por o qual, é modificado por «com suas perteenças»; em (23), «almocreve», núcleo interno do sintagma nominal encabeçado por cujo, é modificado por «dito».

(22) o quall casal com suas perteenças disse que trazia ẽ pregã

(1472, Martins 2001)
(23) vindo de palmela para as virtudes ca por esta banda encontrei hum almocreve e o cujo dito almocreve trazia duas bestas dezocopadas

(CARDS0002 (1827), CLUL 2014)

Outra propriedade identificada em Cardoso para o qual em contextos de coordenação especificante relaciona-se com o antecedente, que, ao contrário do que acontece com o qual do português europeu contemporâneo, pode ser oracional. Mesmo nesse caso, o núcleo interno é sempre nominal, como se verifica em (24).

Com cujo ocorre uma situação idêntica, como se ilustra no exemplo (25), em que o antecedente oracional é recuperado sob a forma nominal «ouCazião».

(24) os ditos cassaaes fforõ cõprados dos dinheiros do dito mosteiro polla quall Razom de derejto perteçem e perteçyam ao dito mosteiro

(1437, Martins 2001)
(25) Paçado o emtrudo paçamos a Almada fazer a Correição, em cuja ouCazião hei de paçar a essa Ci(da)de

(CARDS0292 (1827), CLUL 2014)

Também para ambas as expressões que aqui comparamos, o constituinte relativo pode ser extraposto. Veja-se os exemplos em (26) e (27). 
(26) - Senhor, chegou ally o allmocadẽ, e pareçe-me que diz que lhe he neçessario de vos fallar llogo amte que amanheça. 0 qual comde mamdou que viesse.

(séc. XV, Brocardo 1997)
(27) intregara ao portador desta a quantia de Sem mil reis em moeda papel e fixadas dentro de huma carta pois he para livramento de hum nosso companheiro $\mathrm{q}(\mathrm{eu})$ se acha prezo nessa Cadeia e cujo d(inhei)ro he p(ar)a sua soltura

(CARDS0087 (1824), CLUL 2014)

Ainda em ambos os casos, a força ilocutória da oração relativa pode ser independente da oração que inclui o antecedente. Assim, nas frases em (28) e (29), com o qual e cujo, respetivamente, a oração que contém o antecedente tem um objetivo diretivo e a força ilocutória de 'instruções', enquanto a oração relativa, mantendo-se diretiva, já tem a força ilocutória de 'pedido' (Searle 1975, 346).

(28) Com o teor do qual mandei passar esta carta testemunhável ao dito Bento Henriques, à qual mando que seja dada tanta fé e autoridade, em juízo e fora dele, e onde quer que fôr apresentada, quanta por direito se lhe deve dar. $\underline{\mathbf{0}}$ qual uns e outros assim cumpram e al não façais

(1578, Pereira 1987)
(29) Fasme o favor de ajuntares a demasia q(u)e te pedi q(u)e são 240 o q(u)e te ficarei obrigado pois estou nesta ora sem hum vintem em casa cujo favor eu to agradecerei

(CARDS6069 (1828), CLUL 2014)

Finalmente, a palavra relativa pode, em ambos os casos, co-ocorrer com uma conjunção coordenativa.Vejam-se os exemplos (30) para o qual e (31) para cujo.

(30) custumarõ dauer e ouuerom no dicto Monsteiro bõa raçom e mãtijmeto de pam aluo boroa. carne e viho e o qual mãtijmeto os Priores [...] auiã e som theudos de dar ao dicto conueto

(1364, Martins 2001)
(31) desta tua Molher e que munto te quer $\underline{\text { e }}$ a cucha te dezega para meu emparo de teos filhos

(CARDS5073 (1825), CLUL 2014)

Encontram-se ainda por atestar no Post Scriptum outras propriedades descritas por Cardoso, nomeadamente pied-piping de um Determiner Phrase (DP) (quando um sintagma nominal mais vasto é movido juntamente com a expressão relativa); um nome próprio como núcleo interno da expressão relativa; coordenação do pronome relativo com um grupo nominal; e um antecedente descontínuo. Procurar esta evidência é um dos objetivos do nosso trabalho futuro.

Consideramos, no entanto, que a ausência de atestações para as propriedades acima listadas não inviabiliza a conclusão de que cujo não possessivo se apresenta no corpus como um caso de coordenação especificante, semelhante a $o$ qual. 


\subsection{Evolução diacrónica}

A coordenação especificante com $o$ qual vai desaparecendo da documentação escrita, embora no século XX ainda se encontre em «contextos literários ou registos de grande formalidade» (Veloso 2013, 2096; Brito 1991). Isto é diferente do que acontece com a coordenação especificante com cujo, que, por um lado, permanece ao longo dos séculos XVII, XVIII e XIX (como atestam os exemplos extraídos do Post Scriptum) e, por outro, surge, no século XX (a) condenado nas gramáticas normativas (Moreira 1907); (b) abonado na dialetologia do português europeu (Barreiros 1917) e na descrição de variedades não europeias de português (Brito 2001); e (c) consagrado no registo literário, como se viu no exemplo (16), aqui repetido em (32), a que agora juntamos um outro, em (33).

(32) [...] e foi a mulher quem salvou a situação oferecendo um copo de água à velhota e um anis ao senhor, cujo vestia um casaco de quarto agaloado, no fio, e calças creme compridas de mais [...]

(António Lobo Antunes, Fado Alexandrino, 1983)

(33) Ali [...] corre um rio, o Irati, que, nascido em França, vai desaguar no Erro, espanhol, por sua vez afluente do Aragón, o qual é tributário do Ebro, cujo finalmente levará e lançará no Mediterrâneo as águas de todos.

(José Saramago, Jangada de Pedra, 1986)

\section{Leísmo, laísmo, loísmo no espanhol: distribuição e algumas evidências ${ }^{12}$}

Como caso concreto para o espanhol, escolhemos um problema bem conhecido da sintaxe hispânica: a variação no uso dos pronomes átonos da terceira pessoa. É sabido que esta variação permite estabelecer uma diferença entre os chamados usos canónicos ou etimológicos -formas de acusativo la(s), lo(s) para objeto direto (OD) e formas de dativo le(s) para objeto indireto (OI) - e os chamados usos inovadores ou confundidores, que não respeitam a função sintática do referente, dando lugar, assim, a fenómenos conhecidos como leísmo, laísmo e loísmo. $\mathrm{Na}$ presente secção, levaremos a cabo uma breve análise quantitativa baseada, sobretudo, em duas questões: 1) o grau de difusão dos usos inovadores e 2) sua distribuição geográfica no território peninsular espanhol. Para cumprimento deste

12 Para mais informação, consultar uma versão ampliada deste trabalho em Vaamonde (2015). 
pressuposto, alicerçámos a pesquisa num corpus de 784 cartas de 358 autores diferentes, o que equivale a um total de 4.460 ocorrências.

\subsection{Graus de difusão}

A tabela que se segue permite verificar qual o panorama geral da variação dos pronomes em causa no nosso corpus. Nela encontramos a percentagem de uso de leísmo, laísmo e loísmo organizada por século. De notar que a coluna da direita dá conta da percentagem total de inovação. ${ }^{13}$

Tabela 2: Percentagem de leísmo, laísmo e loísmo

\begin{tabular}{lrrrr}
\hline & leísmo & laísmo & loísmo & inovação total \\
\hline séc. XVI & 23 & 24 & 0 & 16 \\
\hline séc. XVII & 26 & 14 & 1 & 16 \\
\hline séc. XVIII & 27 & 42 & 2 & 22 \\
\hline séc. XIX & 21 & 39 & 0 & 15 \\
\hline TOTAL & 25 & 34 & 1 & 18 \\
\hline
\end{tabular}

Os dados obtidos permitem que teçamos algumas reflexões de ordem geral. Em primeiro lugar, mostramos que tanto o leísmo quanto o laísmo apresentam uma frequência muito maior do que o loísmo, que se revela, definitivamente, como um fenómeno residual. Na literatura (Lapesa 1968, 305; Fernández-Ordóñez 1999, 1320), tem-se considerado recorrentemente o loísmo como uma confusão pronominal de baixa frequência, indo os dados do nosso corpus ao encontro de tal assunção.

Em segundo lugar, importa notar que as percentagens totais de inovação não totalizam $25 \%$ em nenhum dos períodos, o que demonstra um claro predomínio

13 A percentagem de leísmo foi calculada contabilizando o número de formas le(s) com função de OD no total de clíticos com função de OD (foram, portanto, descartados os casos de lo com referente neutro, dado que não entram em competição com nenhuma outra forma pronominal em espanhol). Chegou-se à percentagem de laísmo calculando o número de formas $l a(s)$ em função de OI no total de clíticos com referente feminino em função de OI. Por último, chegou-se à percentagem de loísmo contabilizando o número de formas $l o(s)$ em função de OI no total de clíticos com referente masculino ou neutro em função de OI. As frequências absolutas correspondentes podem ser consultadas no Apêndice 1, no final do artigo. 
das distinções canónicas no emprego dos clíticos. Contudo, a percentagem de inovação com que trabalhamos (18\%) é bastante relevante se a cotejarmos com outros estudos diacrónicos baseados em corpora. A título de exemplo, Flores Cervantes (2006), num corpus predominantemente literário do século XII ao XIX, obtém uma percentagem total de inovação de $12 \%$. Assumindo que qualquer tipo de comparação está circunscrita, em última instância, à língua escrita, parece viável reconhecer diferenças de ocorrência significativas entre o corpus de Flores Cervantes, de marcado caráter literário, e o corpus por nós analisado, composto por cartas privadas de caráter informal. $\mathrm{O}$ uso dos pronomes constitui um marcador sociolinguístico, de tal forma que certas manifestações inovadoras - de laísmo e loísmo- estão associadas, desde há muito, a variedades não standard da língua. É por conseguinte plausível que o estilo familiar e popular das cartas do Post Scriptum possa favorecer - ao contrário do que ocorre na produção literária- a manifestação de traços vernáculos, entre os quais se incluem os usos inovadores dos clíticos.

Por fim, parece-nos interessante ressaltar que a ocorrência de usos laístas se mantém presente nos nossos dados do séc. XIX, atingindo $39 \%$. De notar que a norma académica tinha encetado nos finais do séc. XVIII uma atitude de censura para com os usos confundidores, que não distinguem caso, o que se traduziu numa progressiva regressão do seu emprego na variedade culta da língua. Tal condicionante levou alguns autores a considerar os textos escritos depois dessa época uma fonte ilegítima de dados para o estudo da variação pronominal (Fernández-Ordóñez 1993, 70; 1999, 1322). Claramente, esta condicionante não se aplica ao nosso corpus, cujos textos foram escritos, na sua maioria, por pessoas pertencentes a classes populares, muitas das quais semiletradas. Não estamos, pois, perante uma documentação que reflita uma aproximação progressiva à variedade padrão. A percentagem de $39 \%$ de usos laístas do séc. XIX sugere, em nosso entender, a pouca ou nula influência que as decisões académicas poderiam exercer sobre as variedade linguísticas mais espontâneas dos autores destas cartas.

\subsection{Distribuição geográfica}

A análise dialetal sobre dados contemporâneos revelou a delimitação clara de, pelo menos, duas áreas territoriais no que ao emprego dos pronomes átonos diz respeito: uma zona «distinguidora» (ZD) de caso e uma zona «confundidora» (ZC) (Klein-Andreu 1981, Fernández-Ordóñez 1994). Esta última abarcaria, aproximadamente, a parte ocidental e central de Castela, do sul da Cordilheira Cantábrica a La Mancha, e afetaria, pelo menos, as províncias de Ávila, 
Burgos, Cáceres, Madrid, Palência, Salamanca, Segóvia, Sória, Toledo e Valladolid. ${ }^{14}$

Para o corpus espanhol do Post Scriptum, foi-nos possível averiguar a origem geográfica de 270 autores ( $75 \%$ do total utilizado para este trabalho), tomando sempre a província como indicador de referência. ${ }^{15}$ Os autores procedentes de alguma das províncias citadas foram catalogados dentro da ZC; já os restantes se catalogaram na ZD. Centrámo-nos, assim, em três fenómenos da variação pronominal, exclusivos da ZC: o leísmo inanimado, o laísmo e o loísmo. A tabela 3 mostra que dados nos forneceu o nosso corpus em termos de número de ocorrências.

Tabela 3: Distribuição geográfica de leísmo inanimado, laísmo e loísmo

\begin{tabular}{lrrrrrr}
\hline Área & leísmo (inan.) & $\%$ & laísmo & $\%$ & loísmo & $\%$ \\
\hline$N^{16}$ & 15 & 14 & 19 & 11 & 0 & 0 \\
\hline$Z D$ & 26 & 25 & 15 & 9 & 4 & 29 \\
\hline$Z C$ & 63 & 61 & 136 & 80 & 10 & 71 \\
\hline Total & 104 & 100 & 170 & 100 & 14 & 100 \\
\hline
\end{tabular}

Esperando expandir as nossas contagens, os dados, para já, apontam para uma correlação entre estes três usos inovadores e a atual ZC, pois é dentro dos limites desta que se registam as maiores percentagens. A confirmação de tal tendência, que parece clara no caso do laísmo, poderá indicar um cenário dialetal de variação muito semelhante ao que se conhece na atualidade, podendo sugerir que a difusão da confusão pronominal terá tido início anteriormente à época moderna.

Esta coincidência de isoglossas torna-se ainda mais evidente se atentarmos nos territórios em que nos deparámos com ocorrências de usos inovadores. Nos mapas que abaixo apresentamos, surgem destacadas, à esquerda, as províncias em relação às quais se registou um ou mais autores exemplificando o fenómeno em causa. Para minimizar a possibilidade de falsos positivos (i.e. erros de leitura de manuscrito ou procedências geográficas duvidosas), foram incluídos os mapas

14 Os trabalhos de Fernández-Ordóñez $(1994,1999)$ demonstram um panorama dialetal mais complexo, que inclui variantes dentro da ZC e diversas áreas de transição.

15 Estamos conscientes de que assumir um nível provincial leva à perda de granularidade na análise, porque as fronteiras geográficas e as isoglossas linguísticas raramente coincidem. No entanto, esta estratégia permite-nos trabalhar com um conjunto fechado de opções sem perder excessivo rigor geográfico.

16 NA = não aplicável, por desconhecimento da procedência geográfica. 
da direita, os quais destacam unicamente as províncias com, pelo menos, dois autores diferentes como informantes do fenómeno em questão. Aproveitamos para incluir alguns exemplos:
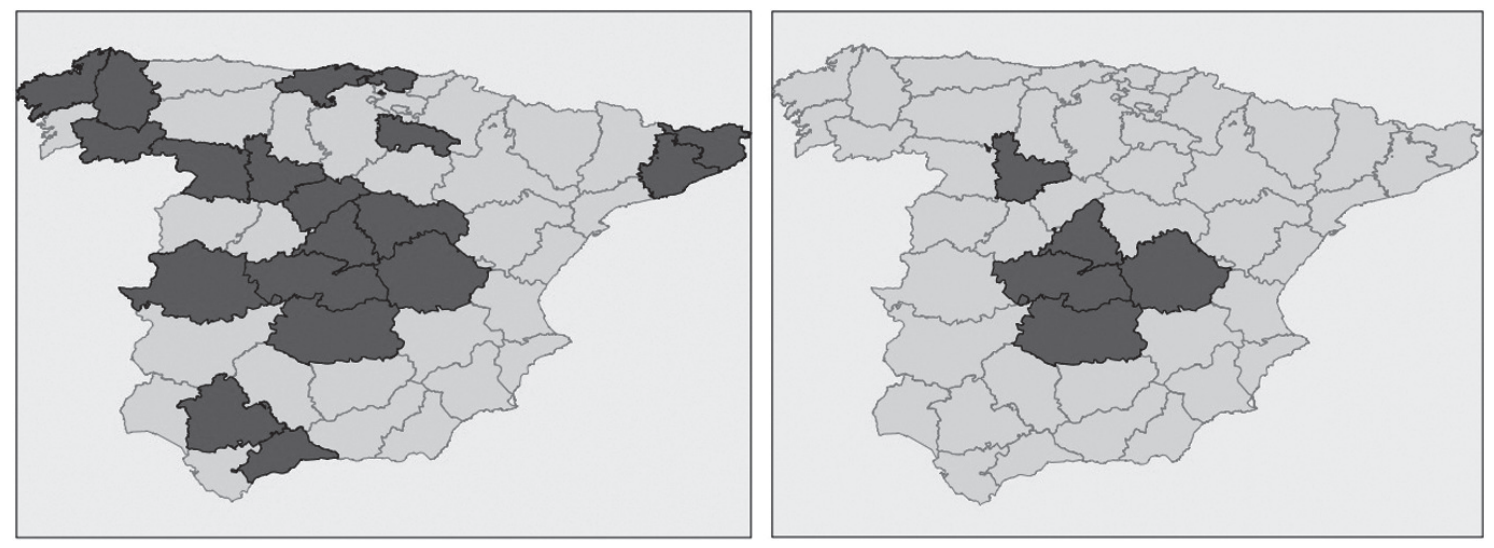

Figura 1: Províncias com autores leístas (apenas leísmo de coisa)

(34) a. quando te se antojo la cosa de regalo y te le trajeron y no le quisiste sino que se le ynbiaste a la enferma hiciste lo que Dabid con el agua.

(PS7091 (1689) autor de Cuenca; CLUL 2014)

b. el cilicio nada incomoda a vezes pero al contado le pondre de modo que no ofenda si se me permite.

(PS8083 (1799) autor de Guadalajara; CLUL 2014)
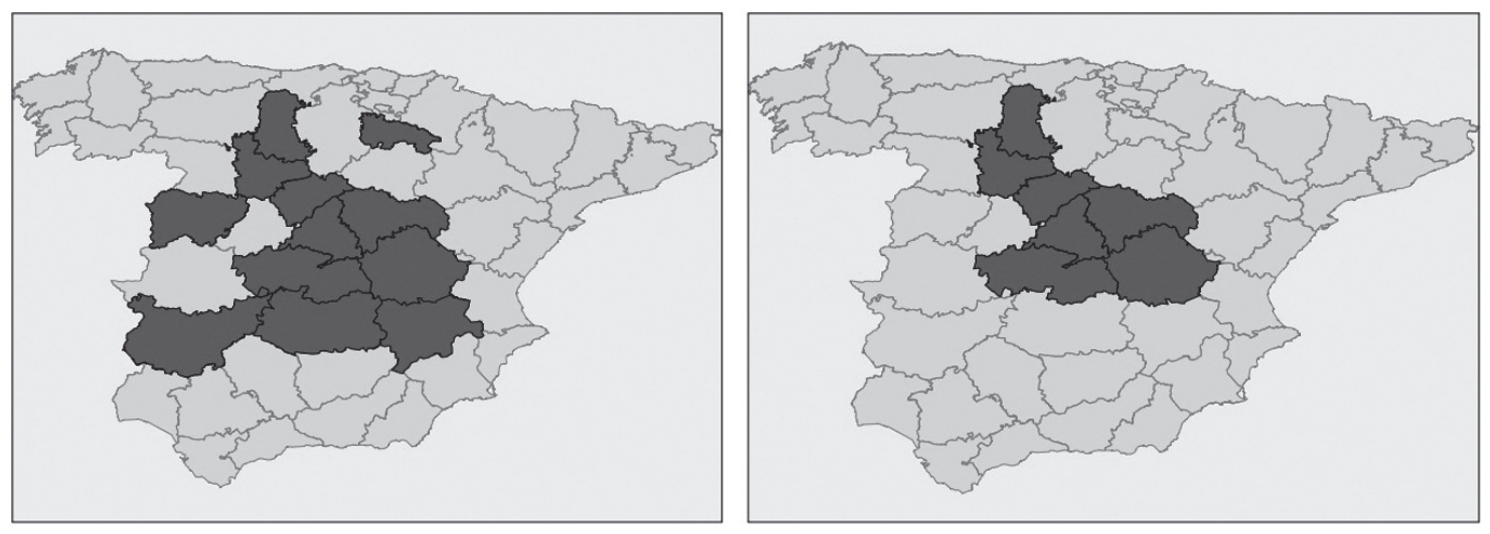

Figura 2: Províncias com autores laístas 
(35) a. Mi muger repite lo mismo q(u)e yo, y q(u)e manda a V(uestra) m(erce)d q(u)e la dijo q(u)e era su verdadera amiga.

(PS9031 (1810) autor de Valladolid; CLUL 2014)

b. y estava guisando unas anguilas y gustandolas savianla bien y bolbio a probar y sintio una pressenzia bellisima que $\mathbf{l a}$ dezia que siempre a de ser golossa y galamera.

(PS6150 (1706) autor de Madrid; CLUL 2014)
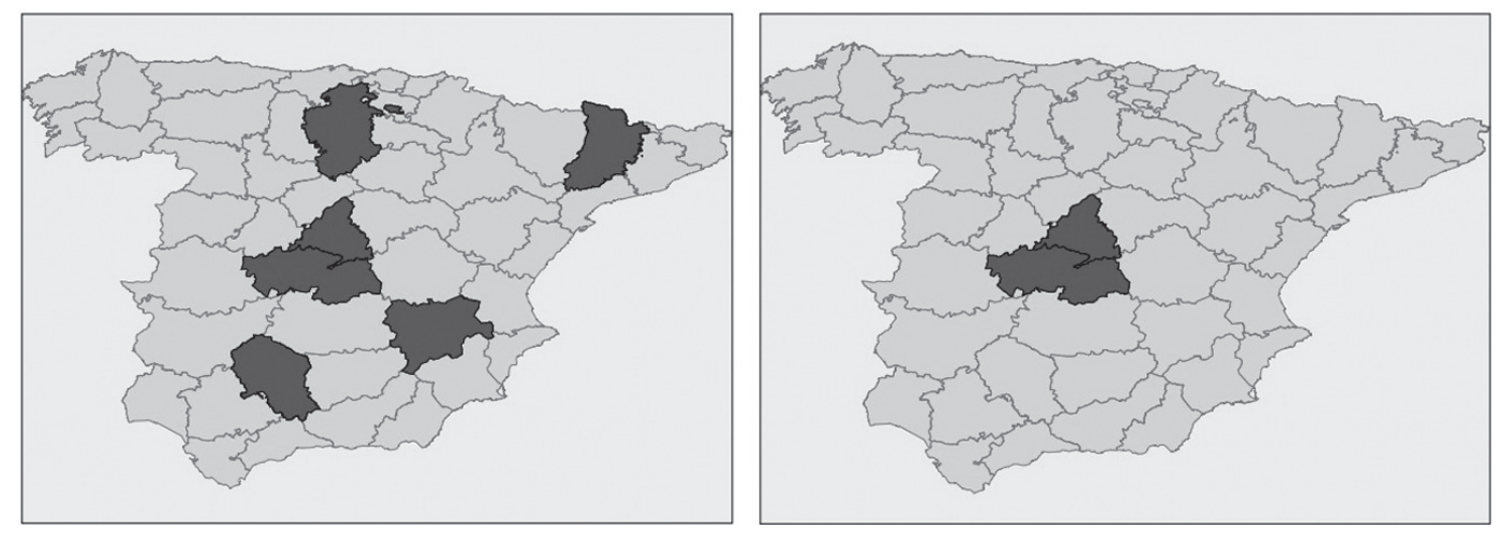

Figura 3: Províncias com autores loístas

(36) a. y aran lo q(ue) quissieren, pues yo solo vine a salir de con ellos. y aun de esta suerte no nos an de dejar. Dios los abra los ojos, q(ue) vien lo an Menester.

(PS6155 (1706) autor de Madrid; CLUL 2014)

b. i al istante que esta cantidad se de io en persona me vere con ustedes u los escrivire un papel avisandolos lo que an de açer.

(PS5019 (1684) autor de Toledo; CLUL 2014)

O Post Scriptum não permite aprofundar quais as origens da confusão pronominal, uma vez que estão documentados casos de leísmo e de loísmo em textos do séc. XIII e de laísmo, em termos fidedignos, desde o séc. XIV (Lapesa 1968; Echenique Elizondo 1981). Não obstante, revela-se muito importante para verificar outros aspetos que dizem respeito à variação. Por um lado, o marco temporal dentro do qual trabalhámos inclui períodos de franco apogeu dos usos inovadores dos pronomes (Matute Martínez 2004, 26) e novos dados sobre a sua difusão e alcance. Por outro lado, temos em mãos informação sobre a procedência geográfica de múltiplos autores, o que nos permitiu desenhar um mapa dialetal da variação numa época não contemporânea. Nesta incursão, necessariamente breve, propusemo-nos explorar esses dados, cumprindo o objetivo de facultar novas evidências sobre o leísmo, laísmo e loísmo, as quais tentaremos confirmar no futuro a partir de um conjunto de dados mais alargado. 


\section{Conclusão}

Terminamos com uma nota sobre o conjunto dos três fenómenos que aqui comentámos, a saber, o marcador discursivo POIS do português e duas estruturas anafóricas, o CUJO em português e os clíticos verbais de terceira pessoa em espanhol, LE(S), LO(S), LA(S). A razão pela qual os três captaram a nossa atenção logo nas primeiras análises teve a ver com o facto que aqui salientámos: apesar de continuarem vivos nas duas línguas, todos se distanciam do que se pode considerar usual nas suas variedades cultas. Mas não podemos deixar de notar, também, que todos três são mecanismos de coesão textual, o que não é certamente um acaso. Os dados das cartas do Post Scriptum contêm advérbios e pronomes desafiantes para os linguistas, mas organizam-se também, sobretudo, em enunciados cuja coesão, logo, coerência, foi instrumental para os autores que os produziram. Um dos nossos próximos desafios é o de conciliarmos análises gramaticais com análises discursivas, e assim contribuirmos para uma futura história das duas línguas na perspetiva dos seus falantes vulgares.

\section{Referências}

Barreiros, Fernando Braga, Vocabulário Barrosão, Revista Lusitana 20:1-2 (1917), 137-161.

Bikel, Daniel, On the Parameter Space of Generative Lexicalized Statistical Parsing Models, PhD Dissertation, University of Pennsylvania, 2004.

Brito, Ana Maria, A Sintaxe das Orações Relativas em Português, Porto, INIC \& CLUP, 1991.

Brito, Ana Maria, Relativas de genitivo no Português Europeu e no Português de Moçambique, in: Gonçalves, Anabela/Correia, Clara Nunes (edd.), Actas do XVI Encontro Nacional da APL, Lisboa, Colibri/APL, 2001, 115-129.

Brito, Ana Maria, Subordinação adverbial, in: Mira Mateus, Maria Helena, et al. (edd.), Gramática da Língua Portuguesa, Lisboa, Caminho, 2003, 695-728.

Camarinhas, Nuno, Juízes e administração da justiça no antigo regime: Portugal e o império colonial, séculos XVII e XVIII, [Lisboa], Fundação Calouste Gulbenkian \& Fundação para a Ciência e a Tecnologia, 2010.

Cardoso, Adriana, Relativas com núcleo interno e relativo de ligação na história do português, in: Frota, Sónia/Santos, Ana Lúcia (edd.), Actas do XXIII Encontro Nacional da Associação Portuguesa de Linguística [Évora, 2007], Lisboa, Colibri/APL, 2008, 77-92.

Cardoso, Adriana, Variation and change in the syntax of relative clauses: new evidence from Portuguese. Tese de Doutoramento, FLUL, 2010.

Cardoso, Adriana, Orações apositivas em português: entre a sincronia e a diacronia, Estudos de Lingüística Galega 3 (2011), 5-29.

Carvalho, Joaquim Ramos de, $A$ jurisdição episcopal sobre leigos em matéria de pecados públicos: as visitas pastorais e o comportamento moral das populações portuguesas de Antigo Regime, Revista Portuguesa de História 24 (1988), 121-163. 
Castro, Ivo, Metodologia do aparato genético, in: Simões, Manuel/Castro, Ivo/Pinto Correia, João David (edd.), Memória dos afectos: homenagem a Giuseppe Tavani, Lisboa, Colibri, 2001, 69-81.

CLUL (ed.), P.S. Post Scriptum: A Digital Archive of Ordinary Writing (Early Modern Portugal and Spain), 2014. Disponível em: http://ps.clul.ul.pt/index.php?action=home.

Collins, Michael, Head-Driven Statistical Models for Natural Language Processing, PhD Dissertation, University of Pennsylvania, 1999.

Costa, Ana Luísa, Um Pois Comentador, in: Veloso, João, et al. (edd.), Textos selecionados. XXIX Encontro Nacional da Associação Portuguesa de Linguística, Porto, APL, 2014, 199-211.

Cunha, Celso/Cintra, Lindley (edd.), Nova Gramática do Português Contemporâneo, Lisboa, Edições João Sá da Costa, 1984.

Echenique Elizondo, María Teresa, El sistema referencial en español antiguo, Revista de Filología Española 61 (1981), 113-157.

Fernández-Ordóñez, Inés, Leísmo, laísmo y loísmo: estado de la cuestión, in: Soriano, Olga Fernández (ed.), Los pronombres átonos, Madrid, Taurus, 1993, 63-96.

Fernández-Ordóñez, Inés, Isoglosas internas del castellano. El sistema referencial del pronombre átono de tercera persona, Revista de Filología Española 74 (1994), 71-125.

Fernández-Ordóñez, Inés, Leísmo, laísmo y loísmo, in: Bosque, Ignacio/Demonte, Violeta (edd.), Gramática descriptiva de la lengua española, Madrid, Espasa Calpe, 1999, 1317-1397.

Fiéis, Alexandra/Lobo, Maria, Para uma diacronia das orações causais e explicativas do português, in: Fiéis, Alexandra/Coutinho, Antónia (edd.), Textos seleccionados. XXIV Encontro Nacional da Associação Portuguesa de Linguística, Lisboa, Colibri/APL, 2009, 265-280.

Flores Cervantes, Marcela, Leísmo, laísmo y loísmo, in: Company Company, Concepción (ed.), Sintaxis histórica de la lengua española. Primera parte: La frase verbal, vol. 1, México, Fondo de Cultura Económica, 2006, 669-749.

Fraser, Bruce, What are discourse markers?, Journal of Pragmatics 31 (1999), 931-952.

Grésillon, Almuth, Élements de critique génétique, Paris, PUF, 1994.

Hespanha, António Manuel, Cultura Jurídica Europeia: Síntese de um Milénio, 2. $\underline{\text { e ed., Mem }}$ Martins, Publicações Europa-América, 2003.

Klein-Andreu, Flora, Distintos sistemas de empleo de le, la, lo. Perspectiva sincrónica, diacrónica y sociolingüística, Thesaurus: boletín del Instituto Caro y Cuervo 36:2 (1981), 284-304.

Kroch, Anthony/Santorini, Beatrice/Delfs, Lauren, The Penn-Helsinki parsed corpus of Early Modern English (PPCEME), Department of Linguistics, University of Pennsylvania, CD-ROM, first edition, 2004.

Lapesa, Rafael, Sobre los orígenes y evolución del leísmo, laísmo y loísmo, in: K. Baldinger (ed.), Festschrift Walther von Wartburg, Tubinga, Max Niemeyer, 1968, 523-551.

Lima, José Pinto de, Grammaticalization, subjectification and the origin of phatic markers, in: Wischer, Ilse/Diewald, Gabriele (edd.), New Reflections on grammaticalization, Amsterdam, John Benjamins, 2002.

Lobo, Maria, Para uma sintaxe das orações causais do português, in: Actas do XVI Encontro Nacional da Associação Portuguesa de Linguística, Lisboa, APL/Colibri, 2001, 291-306.

Lobo, Maria, Subordinação Adverbial, in: Raposo, Eduardo Buzaglo Paiva/Bacelar do Nascimento, Maria Fernanda/Mota, Maria Antónia Coelho da/Segura, Luísa/Mendes, Amália (coords.), Gramática do Português, Lisboa, Fundação Calouste Gulbenkian, 2013. 
Lopes, Óscar, Da partícula pois ao conceito de apodeixis, in: Actas do VII Encontro da Associação Portuguesa de Linguística, Lisboa, Colibri/APL, 1991, 179-192.

Maia, Clarinda de Azevedo, História do Galego-Português, Coimbra, INIC, 1986, 19-295.

Marquilhas, Rita (ed.), Forgotten Letters Years 1900-1974, 2014. Disponível em: http://fly.clul.ul. pt/index.php?page=mainen .

Martín Zorraquino, María Antonia/Portolés Lázaro, José, Los marcadores del discurso, in: Bosque, Ignacio/Demonte, Violeta (edd.), Gramática Descriptiva de la Lengua Española, vol. 3. Entre la oración y el discurso. Morfología, Madrid, Espasa, 1999, 4051-4213.

Martins, Ana Maria, Documentos Portugueses do Noroeste e da Região de Lisboa: Da Produção Primitiva ao Século XVI, Lisboa, Imprensa Nacional - Casa da Moeda, 2001.

Martins, Ana Maria, Relatório da cadeira de História da Língua Portuguesa, apresentado a concurso para Professor Associado, FLUL, 2003.

Matos, Gabriela/Raposo, Eduardo Paiva, Estruturas de coordenação, in: Raposo, Eduardo Buzaglo Paiva/Bacelar do Nascimento, Maria Fernanda/Mota, Maria Antónia Coelho da/Segura, Luísa/Mendes, Amália (coords.), Gramática do Português, Lisboa, Fundação Calouste Gulbenkian, 2013.

Matute Martínez, Carmen, Los sistemas pronominales en español antiguo. Problemas y métodos para una reconstrucción histórica, Madrid, Universidad Autónoma, 2004.

Mendes, Amália, Coesão Textual, in: Raposo, Eduardo Buzaglo Paiva/Bacelar do Nascimento, Maria Fernanda/Mota, Maria Antónia Coelho da/Segura, Luísa/Mendes, Amália (coords.), Gramática do Português, Lisboa, Fundação Calouste Gulbenkian, 2013.

Moreira, Julio, Estudos de Lingua Portuguesa, Lisboa, Livraria Clássica Editora, 1907 (2. ed., 1922).

Nevalainen, Terttu, Historical Sociolinguistics, in: Wodak, Ruth/Johnstone, Barbara/Kerswill, Paul (edd.), The SAGE Handbook of Sociolinguistics, Los Angeles, SAGE, 2011, 279-95.

Peres, João, Sobre conexões proposicionais em Português, in: Maria Brito, Ana, et al. (edd.), O Sentido que a vida faz. Estudos para Óscar Lopes, Porto, Campo das Letras, 1997, 775-787.

Pierazzo, Elena, A rationale of digital documentary editions, Literary and linguistic computing 26:4 (2011), 463-77.

Randall, Beth, CorpusSearch 2, 2005-2007.

Raposo, Eduardo Buzaglo Paiva, Pronomes, in: Raposo, Eduardo Buzaglo Paiva/Bacelar do Nascimento, Maria Fernanda/Mota, Maria Antónia Coelho da/Segura, Luísa/Mendes, Amália (coords.), Gramática do Português, Lisboa, Fundação Calouste Gulbenkian, 2013, 881-918.

Searle, John R., A Taxonomy of Illocutionary Acts, in: Gunderson, Keith (ed.), Language, Mind and Knowledge. Minnesota Studies in the Philosophy of Science, Minneapolis, University of Minnesota Press, 1975, 344-369.

Vaamonde, Gael, Distribución de leísmo, laísmo y loísmo en un corpus diacrónico epistolar, Res Diachronicae 61 (2015), 58-79.

Veloso, Rita, Subordinação Relativa, in: Raposo, Eduardo Buzaglo Paiva/Bacelar do Nascimento, Maria Fernanda/Mota, Maria Antónia Coelho da/Segura, Luísa/Mendes, Amália (coords.), Gramática do Português, Lisboa, Fundação Calouste Gulbenkian, 2013, 2059-2134.

Vries, Mark de, The Syntax of Relativization, Utrecht, LOT, 2002. 


\section{Apêndice}

Apêndice 1: Frequências absolutas e relativas de leísmo, laísmo e loísmo

\begin{tabular}{|c|c|c|c|c|c|c|c|c|}
\hline & leísmo & $\%$ & laísmo & $\%$ & loísmo & $\%$ & inov. total & $\%$ \\
\hline séc. XVI & $80 \quad$ (354) & 23 & (38) & 24 & (157) & 0 & (549) & 16 \\
\hline séc. XVII & $170 \quad(665)$ & 26 & 15 (110) & 14 & (435) & 1 & 189 (1210) & 16 \\
\hline séc. XVIII & 292 (1073) & 27 & $128(308)$ & 42 & (579) & 2 & $430 \quad(1960)$ & 22 \\
\hline séc. XIX & $94 \quad(443)$ & 21 & $18 \quad(46)$ & 39 & (252) & 0 & (741) & 15 \\
\hline TOTAL & 636 (2535) & 25 & $170 \quad(502)$ & 34 & 14 (1423) & 1 & $820 \quad(4460)$ & 18 \\
\hline
\end{tabular}

